\title{
The effect on structural behavior of different slab types for $\mathrm{RC}$ buildings
}

\author{
Hakkı Eşki ${ }^{1}$ iD), Barış Sayın*2 iD, Barış Güneş ${ }^{2}$ iD \\ ${ }^{1}$ Istanbul University-Cerrahpaşa, Institute of Graduate Studies in Science and Engineering, Istanbul, \\ Turkey \\ ${ }^{2}$ Istanbul University-Cerrahpaşa, Department of Civil Engineering, Istanbul, Turkey
}

\begin{abstract}
Considering the vertical- and lateral-effects to RC buildings are exposed, type of construction and geometrical properties of the bearing members is known as the effective parameters in the structural behavior. Slabs defined the bearing members are plane members that transfer the acting loads to the columns and beams. RC slabs are generally classified as beam slab, flat slab and ribbed slab according to the way of transferring the loads in RC buildings under seismic effects. Especially in housing types, ribbed slab system is preferred, while parking type structures are used flat slab system. In this choice, the function of the structure is taken into consideration, and the effect of the selected slab type on the seismic behavior of structures can be ignored. In this respect, the structural behavior of the slab types on the structural behavior must be investigated, extensively. The aim of this study is to examine the effects of slab type on structural behavior in a low-rise RC building. Within the scope of the study, three-dimensional structural model of the examined building is prepared by considering three different slab types, and then analyzed by using linearand nonlinear-analysis methods such as equivalent earthquake load-, mode superposition- and time history analysis-method. As a result of numerical analysis, the parameters that are effective in the structural behavior and construction process - seismic performance, torsional behavior, story drift, etc.- are compared and evaluated the parameters in the selection of slab type in low-rise buildings. Consequently, suggestions for determining the most suitable slab system for the low-rise buildings presented.
\end{abstract}

\section{Keywords}

RC buildings; Slab systems; Structural behavior; Seismic effect; TSC 2007.

Received: 19 September 2019; Accepted: 06 February 2020

ISSN: 2630-5763 (online) C 2020 Golden Light Publishing All rights reserved.

\section{Introduction}

The level of the forces to RC buildings are exposed depends on the geometric characteristics of the structure as well as the characteristics of the loadbearing system. However, in the buildings, magnitude of seismic effect depends on the position of the shear walls in the plan, the shape and the dimensions of the columns, cantilever, the slab types, the openings in the floor system, rebar arrangement and parameters of torsional irregularity are effective. Some structural parameters have been examined to determine the effects of torsional irregularity [1]. In the literature, structural irregularities, structure weight and first period also are compared. It is determined that torsional irregularities occurred when the mass and 
stiffness centers were not overlapped. Additionally, it is observed that the stiffness of the columns increased in the direction of column dimensions. Similarly, it is observed that the spectrum coefficient is in the direction of increasing the stiffness and the base shear force increases accordingly. Therefore, it is important in terms of seismic performance level to choose the appropriate of load-bearing system and slab types based functional properties of RC structures [2].

It is very important to choose the slab system that transfer the loads to the frame system. Choosing the slab type, the purpose of the structure is taken into consideration. Because the types chosen is effective even in the number of storey of RC structure. For example, punching behavior is effective in the head section, which is the point of joining of the column and beam in flat slabs in multi-storey buildings. The behavior of the structure under lateral loads is modeled by adopting rigid diaphragm behavior at floor levels in order to decrease the number of unknown parameters. Low slab thickness in the structure, the presence of large floor spaces in the floors and the ratio of one side to the other in large structures of floor slabs as a rigid diaphragm should be considered. There may be slab openings in different shapes and dimensions due to architectural and structural reasons. Low slab thickness and large openings in the slab prevent diaphragm behavior. The thickness of the slab increases as the load of the slabs increases or the clearance between the supports increases. On the other hand, the cost of RC structure increases as the flooring thickness increases. As the plate thickness increases, the floor system can be divided into smaller areas by placing beams in the floor. In this way, the cost of building can be reduced by decreasing the plate thickness and reducing the dimensions of the load-bearing members [3].

It is an important structural member -slabs subjected to seismic force in RC structures- for the rigidity of the structure. Because the beams are constructed together with the slabs in construction phase, beam cross-sections occur as a table behavior. The slab types used in the building system are known as three types: (i) beam slab, (ii) flat slab, and (iii) ribbed slab. Beam slabs are inconvenient to use in large openings as the beams reduce floor height, Flat slabs can be preferred in large span structures, suitable for wall change according to the intended purpose. However, it is significant issue to design long and heavy consoles. The slab type is not suitable for seismic are due to the punching effect. Mold cost of ribbed slab is low but the material consumption is high. It is the system which is suitable for changing the location of walls. The slab type is very suitable for large openings and do not have sufficient performance in terms of seismic resistance.

In Turkish Seismic Code (TSC) 2007 [4], seismic analysis methods include earthquake load, mode superposition and time history analysis methods. In the equivalent earthquake load method, the earthquake load affecting mass center of the structure is calculated approximately and it is simplified of the modal analysis. This method cannot be used in some types of irregular structures specified in the regulations. In a study in the literature, the solution methods stated in the earthquake code are transferred and the process steps are given [5]. As a result of the analyzes, natural vibration periods were determined as $T_{1 x}=$ $0.92 \mathrm{~s}$ and $T_{1 y}=0.85 \mathrm{~s}$ in $x$ - and $y$-directions. As the building period is high, the base shear force applied to the building remained low compared to the maximum value in the spectrum.

Modal analysis is a method used to determine the dynamic characteristics of a structure, including the natural frequency, the damping values and the mode format, which is a value dependent on the structural deformations. It can also be called multimode analysis. Unlike the equivalent earthquake load method, all vibration periods and mode shapes are taken into account in the mode combination method. In the time history analysis method, previously recorded or simulated earthquake ground motions can be used for the linear elastic or non-linear elastic earthquake calculation of building type structures. In the time history analysis approach, it is considered the nonlinear effect of the structure. 
In the present study, the effect of slab types on structural behavior is investigated numerically for low-rise RC buildings. To this end, structural models are prepared by using beam slab, flat slab, and ribbed slab, and then the obtained analysis results for prepared each model are compared.

\section{Numerical modelling}

TS 500 [6] and TS498 [7] standards were used to calculation rules and determine the loads subjected to the structure. The seismic resistant load design is based on the TSC 2007. Building design was prepared using Sta4-Cad software [8]. The building has five storey and the arrangement of the loadbearing members are symmetric. 3D view of the structural model prepared for the study is presented in Fig. 1. Material properties, design parameters and loading combinations are given in Tables 1-3, respectively.

\section{Analysis results}

\subsection{Checking of torsional irregularity}

Torsional irregularities developed in the $x$ - and $y$ directions to the beam-, flat-, and ribbed-slabs are given in Tables 4 to 6 . Based on the results, torsional irregularity occurred in all floors of the beam slab, whereas torsion irregularity occurred in the upper floors of the flat slab, this irregularity doesn't occur in the lower floors, and in the flooring of the ribbed slab there is no torsional irregularity.

\subsection{Checking of stiffness irregularity among neighboring floors}

In the building with different slab types, checking is performed in the $x$ - and $y$-directions for each slab, and the ratio of the average relative slab displacement to the average interstory drift in the upper or lower floor is found to be less than 2.0. As a result, it is concluded that there is no stiffness irregularity in the structure.

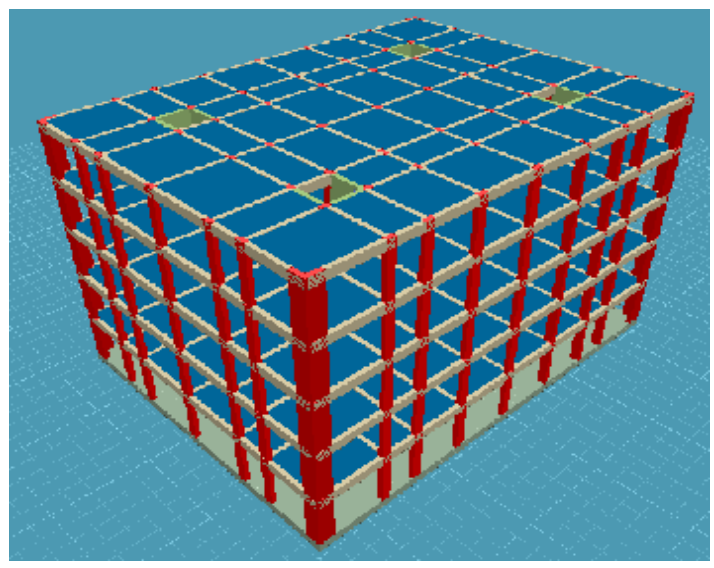

Fig. 1. 3D model of the building

Table 1. Material properties

\begin{tabular}{lcc}
\hline Member & $\begin{array}{c}\text { Density } \\
\left(\mathrm{kN} / \mathrm{m}^{3}\right)\end{array}$ & $\begin{array}{c}\text { Modulus of } \\
\text { elasticity } \\
(\mathrm{MPa})\end{array}$ \\
\hline Column & 20 & 285240 \\
Beam & 20 & 285240 \\
Shear wall & 20 & 285240 \\
Slab & 20 & 285240 \\
Foundation & 25 & 285240 \\
Brick wall & 10 & 100000 \\
\hline
\end{tabular}

Table 2. Analysis parameters

\begin{tabular}{lc}
\hline Parameter & Value \\
\hline Seismic zone coefficient & 0.1 \\
Seismic load reduction factor $\left(\mathrm{R}_{\mathrm{x}} / \mathrm{R}_{\mathrm{y}}\right)$ & 7 \\
Building importance factor $(\mathrm{I})$ & 1 \\
Spectrum characteristic periods $\left(\mathrm{T}_{\mathrm{a}} / \mathrm{T}_{\mathrm{b}}\right)$ & 3.75 \\
Live load coefficient $(n)$ & 0.3 \\
Vertical deposition coefficient $\left(\mathrm{t} / \mathrm{m}^{3}\right)$ & 1000 \\
Allowable bearing value, $\sigma_{z}\left(\mathrm{t} / \mathrm{m}^{2}\right)$ & 10 \\
\hline
\end{tabular}

Table 3. Loading combinations

\begin{tabular}{ll}
\hline Combination & Value \\
\hline COMB 1 & $1.4 \mathrm{G}+1.6 \mathrm{Q}$ \\
COMB 2 & $1.4 \mathrm{G}+1.6 \mathrm{Q}+1.6 \mathrm{~S}$ \\
COMB 3 & $1.0 \mathrm{G}+1.2 \mathrm{Q}+1.2 \mathrm{~T}$ \\
COMB 4 & $1.0 \mathrm{G}+1.0 \mathrm{Q}+1.0 \mathrm{E}$ \\
COMB 5 & $1.0 \mathrm{G}+1.0 \mathrm{Q}+1.0 \mathrm{~S}+1.0 \mathrm{E}$ \\
COMB 6 & $0.9 \mathrm{G}+1.0 \mathrm{E}$ \\
COMB 7 & $1.0 \mathrm{G}+1.3 \mathrm{Q}+1.3 \mathrm{~W}$ \\
COMB 8 & $1.0 \mathrm{G}+1.3 \mathrm{Q}+1.0 \mathrm{~S}+1.3 \mathrm{~W}$ \\
COMB 9 & $0.9 \mathrm{G}+1.3 \mathrm{~W}$ \\
COMB 10 & $0.9 \mathrm{G}+0.9 \mathrm{~S}+1.3 \mathrm{~W}$ \\
\hline
\end{tabular}


Table 4. Torsional irregularities in beam slab

\begin{tabular}{ccccccc}
\hline Storey & $\left(\Delta_{i}\right)_{\max }$ & $\left(\Delta_{i}\right)_{\min }$ & $\left(\Delta_{i}\right)_{\text {avg }}$ & $\eta_{b i}$ & Torsional & Eccentricity \\
\hline 5 & 0.0002540 & 0.0001828 & 0.0002184 & $1.16<1.2$ & & \\
4 & 0.0003123 & 0.0002270 & 0.0002696 & $1.16<1.2$ & & \\
3 & 0.0003436 & 0.0002515 & 0.0002975 & $1.15<1.2$ & None & $5 \%$ \\
2 & 0.0003319 & 0.0002457 & 0.0002888 & $1.15<1.2$ & & \\
1 & 0.0002230 & 0.0001693 & 0.0001962 & $1.14<1.2$ & \\
\hline$\eta_{b i}=\frac{\left(\Delta_{i}\right)_{\max }}{\left(\Delta_{i}\right)_{\text {avg }}}>1.2$ and $\left(\Delta_{i}\right)_{\text {avg }}=\frac{\left(\Delta_{i}\right)_{\max }+\left(\Delta_{i}\right)_{\min }}{2}$ & & &
\end{tabular}

Table 5. Torsional irregularities in flat slab

\begin{tabular}{ccccccc}
\hline Storey & $\left(\Delta_{i}\right)_{\max }$ & $\left(\Delta_{i}\right)_{\min }$ & $\left(\Delta_{i}\right)_{\text {avg }}$ & $\eta_{b i}$ & Torsional & Eccentricity \\
\hline 5 & 0.0000527 & 0.0000373 & 0.0000450 & $1.17<1.2$ & & \\
4 & 0.0000623 & 0.0000463 & 0.0000543 & $1.15<1.2$ & & \\
3 & 0.0000665 & 0.0000512 & 0.0000588 & $1.13<1.2$ & None & $5 \%$ \\
2 & 0.0000633 & 0.0000506 & 0.0000570 & $1.11<1.2$ & & \\
1 & 0.0000454 & 0.0000377 & 0.0000415 & $1.09<1.2$ & & \\
\hline
\end{tabular}

Table 6. Torsional irregularities in ribbed slab

\begin{tabular}{ccccccc}
\hline Storey & $\left(\Delta_{i}\right)_{\max }$ & $\left(\Delta_{i}\right)_{\min }$ & $\left(\Delta_{i}\right)_{\text {avg }}$ & $\eta_{b i}$ & Torsional & Eccentricity \\
\hline 5 & 0.0002400 & 0.0001994 & 0.0002197 & $1.09<1.2$ & & \\
4 & 0.0002983 & 0.0002500 & 0.0002742 & $1.09<1.2$ & & \\
3 & 0.0003310 & 0.0002790 & 0.0003050 & $1.09<1.2$ & None & $5 \%$ \\
2 & 0.0003227 & 0.0002741 & 0.0002984 & $1.08<1.2$ & & \\
1 & 0.0002200 & 0.0001897 & 0.0002049 & $1.07<1.2$ & & \\
\hline
\end{tabular}

\subsection{Comparison of period values}

Mode joining method is a modal analysis, it is obtained by statistically combining the maximum contributions of magnitudes such as total earthquake load, floor shear force, internal force components and displacements. In Tables 7 to 9, period values formed in structures consisting of beam-, flat- and ribbed-slabs are given according to nine mode values. According to the results, the mass participation rates for the considered structures are more than $90 \%$ in the $x$ - and $y$ directions, and the dynamic mass ratios of the structures are sufficient. This shows that there is enough mode number for analysis.

\subsection{Comparison of displacements}

In TSC 2007 code, for structures with high ductility level, it is foreseen that elastic earthquake loads due to high energy consumption due to ductility is reduced and multiplied by a larger coefficient. As a result of the analysis of the models prepared for the three different types of slabs examined, the natural period values obtained for the beam-, flat- and ribbed-slabs are, respectively, $0.32,0.24$ and 0.33 seconds. The displacement values obtained for three different slabs are given in Tables 10 to 12 .

Due to the forces the structure is exposed, lateral displacements are provided in the $x$ - and $y$ directions. Examining the lateral displacements on all floors, the average displacement in the $y$ direction in the beam slab and flat slab models is greater than the average displacement in the $x$ direction. Comparing the models, the lateral displacement is provided in the ribbed slab structure, while the least average lateral displacement is observed in the flat slab. 
Table 7. Periods for beam slab

\begin{tabular}{cccccccccc}
\hline Mode & 1 & 2 & 3 & 4 & 5 & 6 & 7 & 8 & 9 \\
\hline$\omega(\mathrm{rad} / \mathrm{s})$ & 19.56 & 21.62 & 24.20 & 64.66 & 76.53 & 82.97 & 120.44 & 150.23 & 160.16 \\
$T(\mathrm{~s})$ & 0.3213 & 0.2906 & 0.2596 & 0.0972 & 0.0921 & 0.0757 & 0.0522 & 0.0418 & 0.0392 \\
$M_{x r} \%$ & 79.515 & 0.001 & 0.055 & 14.382 & 0.000 & 0.005 & 4.106 & 0.000 & 0.001 \\
$M_{y r} \%$ & 0.000 & 76.988 & 0.227 & 0.000 & 15.883 & 0.046 & 0.000 & 4.829 & 0.013 \\
\hline$\Sigma$
\end{tabular}

Table 8. Periods for flat slab

\begin{tabular}{cccccccccc}
\hline Mode & 1 & 2 & 3 & 4 & 5 & 6 & 7 & 8 & 9 \\
\hline$\omega(\mathrm{rad} / \mathrm{s})$ & 25.84 & 42.72 & 43.85 & 99.82 & 142.82 & 154.42 & 198.66 & 261.06 & 283.20 \\
$T(\mathrm{~s})$ & 0.2431 & 0.1471 & 0.1433 & 0.0629 & 0.0440 & 0.0407 & 0.0316 & 0.0241 & 0.0222 \\
$M_{x r} \%$ & 0.000 & 2.195 & 77.753 & 0.000 & 14.716 & 0.011 & 0.000 & 3.722 & 0.000 \\
$M_{y r} \%$ & 74.391 & 0.003 & 0.000 & 19.306 & 0.000 & 0.001 & 4.430 & 0.000 & 1.502 \\
\hline$\Sigma M_{x r}=98.40 \%, \Sigma M_{y r}=99.63 \%$ & & & & & & &
\end{tabular}

Table 9. Periods for ribbed slab

\begin{tabular}{cccccccccc}
\hline Mode & 1 & 2 & 3 & 4 & 5 & 6 & 7 & 8 & 9 \\
\hline$\omega(\mathrm{rad} / \mathrm{s})$ & 19.28 & 21.25 & 23.65 & 63.38 & 74.63 & 80.68 & 117.49 & 145.70 & 155.10 \\
$T(\mathrm{~s})$ & 0.3259 & 0.2957 & 0.2657 & 0.0991 & 0.0842 & 0.0779 & 0.0535 & 0.0431 & 0.0405 \\
$M_{x r} \%$ & 79.766 & 0.002 & 0.078 & 14.157 & 0.000 & 0.006 & 4.070 & 0.000 & 0.001 \\
$M_{y r} \%$ & 0.001 & 77.114 & 0.340 & 0.000 & 15.698 & 0.070 & 0.000 & 4.771 & 0.020 \\
\hline
\end{tabular}

$\Sigma M_{x r}=98.08 \%, \Sigma M_{y r}=98.01 \%$

Table 10. Displacements in the building (Case of beam slab)

\begin{tabular}{ccccccc}
\hline \multirow{2}{*}{ Storey } & \multicolumn{2}{c}{$\Delta$ Y left $(\mathrm{m})$} & \multicolumn{2}{c}{$\Delta$ Y right $(\mathrm{m})$} & \multicolumn{2}{c}{$\Delta$ Y average $(\mathrm{m})$} \\
\cline { 2 - 7 } & $x$ & $y$ & $x$ & $y$ & $x$ & $y$ \\
\hline 5 & 0.0001497 & 0.0001828 & 0.0002556 & 0.0002540 & 0.0002026 & 0.0002184 \\
4 & 0.0001716 & 0.000227 & 0.0003008 & 0.0003123 & 0.0002362 & 0.0002696 \\
3 & 0.0001779 & 0.0002515 & 0.0003185 & 0.0003436 & 0.0002482 & 0.0002975 \\
2 & 0.0001581 & 0.0002457 & 0.0002909 & 0.0003319 & 0.0002245 & 0.0002888 \\
1 & 0.0000948 & 0.0001693 & 0.0001785 & 0.0002230 & 0.0001366 & 0.0001962 \\
\hline
\end{tabular}

Table 11. Displacements in the building (Case of flat slab)

\begin{tabular}{ccccccc}
\hline \multirow{2}{*}{ Storey } & \multicolumn{2}{c}{$\Delta$ Y left $(\mathrm{m})$} & \multicolumn{2}{c}{$\Delta$ Y right $(\mathrm{m})$} & \multicolumn{2}{c}{$\Delta$ Y average $(\mathrm{m})$} \\
\cline { 2 - 7 } & $x$ & $y$ & $x$ & $y$ & $x$ & $y$ \\
\hline 5 & 0.0000494 & 0.0001639 & 0.0000390 & 0.0001842 & 0.0000442 & 0.0001740 \\
4 & 0.0000594 & 0.0001708 & 0.0000475 & 0.0001927 & 0.0000534 & 0.0001817 \\
3 & 0.0000641 & 0.0001626 & 0.0000517 & 0.0001840 & 0.0000579 & 0.0001733 \\
2 & 0.0000619 & 0.0001355 & 0.0000504 & 0.0001540 & 0.0000562 & 0.0001447 \\
1 & 0.0000449 & 0.0000777 & 0.0000370 & 0.0000895 & 0.0000410 & 0.0000836 \\
\hline
\end{tabular}


Table 12. Displacements in the building (Case of ribbed slab)

\begin{tabular}{ccccccc}
\hline \multirow{2}{*}{ Storey } & \multicolumn{2}{c}{$\Delta$ Y left $(\mathrm{m})$} & \multicolumn{2}{c}{$\Delta$ Y right $(\mathrm{m})$} & \multicolumn{2}{c}{$\Delta$ Y average $(\mathrm{m})$} \\
\cline { 2 - 7 } & $x$ & $y$ & $x$ & $y$ & $x$ & $y$ \\
\hline 5 & 0.0002069 & 0.0001886 & 0.0002501 & 0.0002443 & 0.0002285 & 0.0002164 \\
4 & 0.0002587 & 0.0002187 & 0.0003102 & 0.0002876 & 0.0002844 & 0.0002531 \\
3 & 0.0002882 & 0.0002292 & 0.0003435 & 0.0003050 & 0.0003159 & 0.0002671 \\
2 & 0.0002828 & 0.0002065 & 0.0003345 & 0.0002791 & 0.0003087 & 0.0002428 \\
1 & 0.0001957 & 0.0001260 & 0.0002278 & 0.0001727 & 0.0002118 & 0.0001493 \\
\hline
\end{tabular}

Table 13. Seismic loads provided for three slab types

\begin{tabular}{|c|c|c|c|c|c|c|c|c|c|c|c|c|}
\hline \multirow{3}{*}{ Storey } & \multicolumn{6}{|c|}{ Modal analysis } & \multicolumn{6}{|c|}{ Equivalent earthquake load method } \\
\hline & \multicolumn{2}{|c|}{ Beam slab } & \multicolumn{2}{|c|}{ Flat slab } & \multicolumn{2}{|c|}{ Ribbed slab } & \multicolumn{2}{|c|}{ Beam slab } & \multicolumn{2}{|c|}{ Flat slab } & \multicolumn{2}{|c|}{ Ribbed slab } \\
\hline & $x$ & $y$ & $x$ & $y$ & $x$ & $y$ & $x$ & $y$ & $x$ & $y$ & $x$ & $y$ \\
\hline 5 & 21.7 & 22.1 & 50.1 & 50.9 & 24.1 & 24.7 & 25.2 & 25.2 & 50.1 & 60.2 & 30.1 & 30.1 \\
\hline 4 & 15.8 & 17.5 & 35.3 & 32.8 & 17.4 & 16.9 & 17.5 & 17.5 & 35.3 & 43.1 & 21.2 & 21.2 \\
\hline 3 & 11.7 & 11.1 & 25.7 & 22.8 & 12.9 & 12.3 & 11.7 & 11.7 & 25.7 & 32.3 & 15.9 & 15.9 \\
\hline 2 & 7.9 & 7.4 & 18.3 & 16.0 & 8.8 & 8.2 & 5.8 & 5.8 & 18.3 & 21.5 & 10.6 & 10.6 \\
\hline 1 & 4.1 & 3.8 & 10.2 & 8.9 & 4.4 & 4.1 & 28.1 & 28.1 & 10.2 & 10.7 & 5.3 & 5.3 \\
\hline$\sum$ & 61.3 & 60.1 & 139.9 & 131.7 & 67.8 & 66.4 & 88.4 & 88.4 & 139.9 & 168.1 & 83.2 & 83.2 \\
\hline
\end{tabular}

Units in ton

Table 14. Shear base forces provided for three slab types

\begin{tabular}{ccrrrrrrrrrrrr}
\hline \multirow{3}{*}{ Storey } & $H$ & $H(\mathrm{~m})$ & \multicolumn{4}{c}{ Beam slab } & \multicolumn{4}{c}{ Flat slab } & \multicolumn{4}{c}{ Ribbed slab } \\
\cline { 3 - 14 } & & $F_{x}$ & $F_{x} \times H$ & \multicolumn{1}{c}{$F_{x}$} & $F_{x} \times H$ & $F_{x}$ & $F_{x} \times H$ & $F_{x}$ & $F_{x} \times H$ & $F_{x}$ & $F_{x} \times H$ & $F_{x}$ & $F_{x} \times H$ \\
\hline 5 & 12 & 21.7 & 260.5 & 22.2 & 266.1 & 51.1 & $613.7-$ & 52.0 & 624.5 & 23.1 & 277.4 & 23.6 & 283.4 \\
4 & 9 & 15.8 & 142.9 & 15.3 & 138.2 & 35.9 & 323.8 & 33.5 & 301.6 & 17.0 & 153.1 & 16.4 & 148.0 \\
3 & 6 & 11.7 & 70.6 & 11.1 & 66.9 & 26.2 & 157.7 & 23.3 & 139.9 & 12.6 & 75.8 & 11.9 & 71.8 \\
2 & 3 & 7.9 & 23.9 & 7.5 & 22.5 & 18.7 & 56.2 & 16.4 & 49.2 & 8.6 & 25.8 & 8.0 & 24.1 \\
1 & B & - & - & - & - & - & - & - & - & - & - & - & - \\
\hline
\end{tabular}

B: Basement, Units in ton

\subsection{Comparison of analysis methods}

The results of modal analysis and equivalent earthquake load method are obtained based on seismic forces subjected to the structures, and presented in Table 13. The seismic forces of $x$ - and $y$-directions as a result of modal analysis, it is seen that these values are close to each other but the earthquake force in the $x$-direction is more than the earthquake force in the $y$-direction.

In the equivalent earthquake method, the earthquake forces in the $x$ - and $y$-direction give the same results in the beam slab and flat slab, while the seismic force in the $y$-direction in the flat slab has values higher than the earthquake force in the $x$-direction. The earthquake forces resulting from the equivalent earthquake method is obtained greater seismic forces than those of the modal analysis.

\subsection{Comparison of shear forces}

Seismic shear forces provided on each slab based on seismic forces affecting the structure are examined. It is determined that only shear force in the $\mathrm{y}$ direction in the 5th floor is more than shear force in the $x$-direction. It is calculated that shear force in the $x$-direction in other slabs is more than 
in the $y$-direction. Examining shear forces in the floors, the highest shear force occurred in the flat beam slab, and the least shear force in beam slab.

The checking of the interstory drift of the buildings was performed in the form given in TSC 2007 based on the displacements in each slab. The storey height in the designed buildings is $3 \mathrm{~m}$. Behavior coefficient, $\mathrm{R}$ is determined as 7 . The checking and comparison of the interstory drift of the slab in $x$ - and $y$-direction are shown in Table 15. As can be seen from the values and graphics given above, the interstory drifts for three buildings in the $x$ - and $y$-directions are well below 0.02 . There is no negative situation in the buildings in terms of interstory drift.

\subsection{Comparison of P-delta effect}

The P-delta effect value of the building is calculated and in the structures with different flooring systems, the second order effects are checked in the $x$ - and $y$-directions of the building. The data obtained from the studies are given in Table 16. Accordingly, three building models with different slab types have values well below the required ratio $\theta_{i}=0.12$ for the emergence of P-delta effects.

\section{Conclusions}

In the study, the numerical models are prepared and analyzed in the five storey RC building by selecting the type of beam slab, flat slab and ribbed slab. The results for natural period, floor displacement, shear base and effective seismic force are compared. The following conclusions can be drawn:

- The displacements in the $x$ - and $y$-directions in three slab types, the maximum average lateral displacement is formed in the ribbed slab selected in building, while the least average lateral displacement is formed in the flat slab selected in the building.

- The extreme earthquake force is formed in the flat slab, while the lowest earthquake force occurred in the beam slab. Moreover, the earthquake force values obtained by using the equivalent earthquake load method in three models are obtained to be higher than the earthquake force values obtained from the modal analysis.

Table 15. Interstory drift $\left(\delta_{i, \max } / H_{i}\right)$

\begin{tabular}{ccccccc}
\hline \multirow{2}{*}{ Storey } & \multicolumn{2}{c}{ Beam slab } & \multicolumn{2}{c}{ Flat slab } & \multicolumn{2}{c}{ Ribbed slab } \\
\cline { 2 - 7 } & $x$ & $y$ & $x$ & $y$ & $x$ & $y$ \\
\hline 5 & 0.00042 & 0.0004 & 0.000086 & 0.00025 & 0.00043 & 0.00036 \\
4 & 0.00035 & 0.0003 & 0.000071 & 0.00019 & 0.00036 & 0.00029 \\
3 & 0.00026 & 0.0002 & 0.000053 & 0.00014 & 0.00027 & 0.00021 \\
2 & 0.00016 & 0.0002 & 0.000033 & 0.00008 & 0.00017 & 0.00013 \\
1 & 0.00007 & 0.0001 & 0.000014 & 0.00003 & 0.00007 & 0.00005 \\
\hline
\end{tabular}

Table 16. P-delta effect $\left(\theta_{i}\right)$ (eccentricity 5\%)

\begin{tabular}{ccccccc}
\hline \multirow{2}{*}{ Storey } & \multicolumn{2}{c}{ Beam slab } & \multicolumn{2}{c}{ Flat slab } & \multicolumn{2}{c}{ Ribbed slab } \\
\cline { 2 - 7 } & $x$ & $y$ & $x$ & $y$ & $x$ & $y$ \\
\hline 5 & 0.00142 & 0.00129 & 0.00028 & 0.00106 & 0.00143 & 0.00132 \\
4 & 0.00202 & 0.00177 & 0.00040 & 0.00135 & 0.00205 & 0.00182 \\
3 & 0.00255 & 0.00215 & 0.00050 & 0.00152 & 0.00261 & 0.00222 \\
2 & 0.00284 & 0.00225 & 0.00055 & 0.00147 & 0.00292 & 0.00234 \\
1 & 0.00000 & 0.00000 & 0.00000 & 0.00000 & 0.00000 & 0.00000 \\
\hline
\end{tabular}


- The extreme shear force affects the flat slab, while the least shear force affects the beam slab. Similarly, examining the earthquake shear forces acting on $x$ - and $y$-direction, it is seen that the shear force in $x$-direction is generally higher than the earthquake shear force in the $y$ direction. In addition, when the shear forces provided at the bottom of the curtains are examined, the maximum shear base shear force is provided on the ribbed floor selected in the in the building and at least the shear base shear force is provided on the flat slab selected in the building.

- The irregularities do not exceed the limit values in the TSY 2007. Similarly, it is determined that the lateral displacement, earthquake force, shear force values of the structure do not exceed the limit values in the TSY 2007.

\section{Declaration of conflicting interests}

The author(s) declared no potential conflicts of interest with respect to the research, authorship, and/or publication of this article.

\section{References}

[1] Erdem H. Effects of Torsional irregularity (A1) on reinforced concrete structure behavior. MSc Thesis. Çukurova University, 2016 (in Turkish).

[2] Ersoy U. Reinforced Concrete II: Slabs, Evrim Press, 2006 (in Turkish).

[3] Yaşaoğlu FG. The effect of flooring types on behavior in reinforced concrete structures with different bearing systems. MSc Thesis. Istanbul Technical University, 2015 (in Turkish).

[4] TSC 2007: Turkish earthquake-resistant code specification for buildings to be built in seismic zones. Ministry of Public Works and Settlement, 2007.

[5] Turan D. Design of a reinforced concrete structure according to equivalent earthquake load method and modal combination method. MSc Thesis. Istanbul Technical University, 2012 (in Turkish).

[6] TS 500: Requirements for design and construction of reinforced concrete structures, TSE (Turkish Standards Institute), Ankara, Turkey, 2000 (in Turkish).

[7] TS 498: The loads and loading cases due to use and occupancy in residential and public buildings, TSE (Turkish Standards Institute), 1997, (in Turkish).

[8] Sta4-Cad (2017). Structural Analysis for Computer Aided Design. STA Co. 